The female is larger, lacks the bands on the antennæ and has less distinct markings on the abdomen. (Fig. 2;2 shows the wing of the female.)

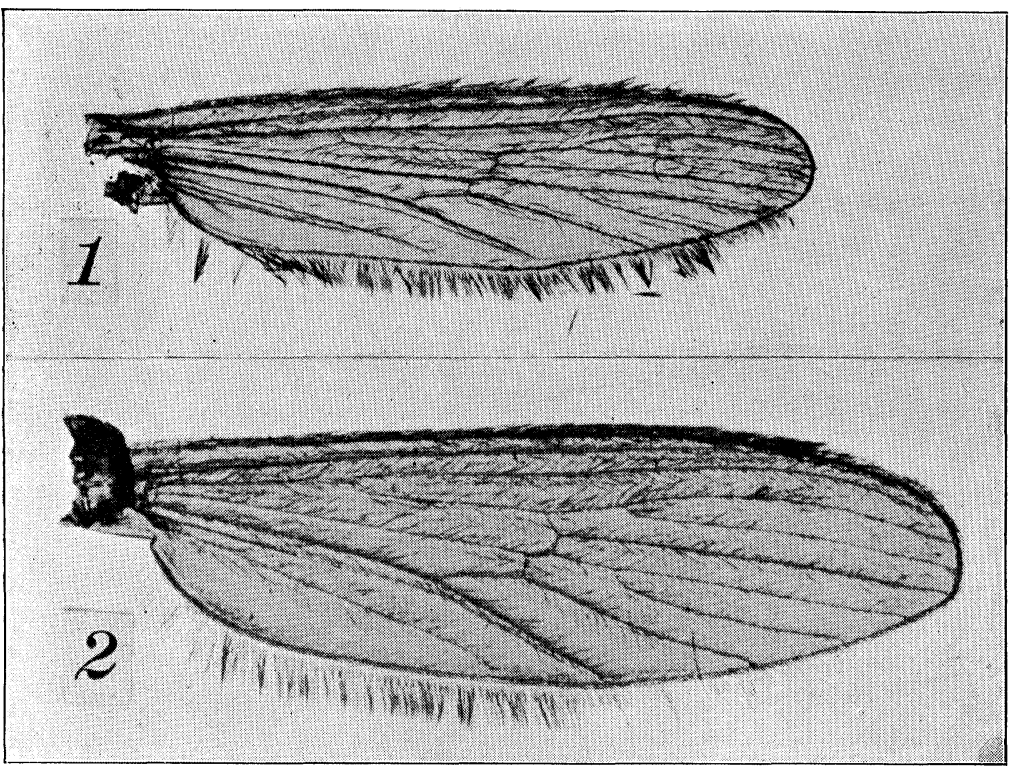

Fig. 2. Wings of Corethra albipes Johannsen. 1, Wing of male, enlarged 17 times; 2, Wing of female, enlarged 23 times.

\title{
A NEW MELITTOBIA FROM QUEENSLAND, AUSTRALIA.
}

\author{
By A. A. Girault, \\ Nelson (Cairns), North Queensland.
}

Melittobia australica, nov.

Normal position.

Female:-Length, $1.1 \mathrm{~mm}$.; usual in size for the genus. General color dark brown-black, including the antennæ; proximal two thirds of abdomen lighter, greyish yellow; legs yellow, the coxæ and femora washed with dilute dusky; venation grayish; fore 
wings lightly, uniformly, fumated throughout, the posterior wings hyaline. Eyes dark red. Distal tarsal joint not darker than the rest of the tarsus. Fore and posterior wings densely, uniformly ciliate in the disk, the marginal cilia of the fore wings short, those of the posterior wings nearly twice longer yet the longest here (middle of caudal margin) are not longer than a fourth of the blade's greatest width (across apex of the venation); they are moderately short. The fore wings are about two and a quarter times longer than wide. Stigmal vein distinct; postmarginal vein absent; other veins normal. The posterior wings bear about twelve lines of discal ciliation across its widest part. Two distinct parallel lines of discal cilia in the fore wing run along the caudal margin opposite the venation, while beneath the slender portion of the submarginal vein are two short lines of minute cilia, one on each side of the base of the cephalic of the two long lines just noted. Posterior wings broad. Distal joint of tarsi longest of the four. Parapsidal furrows complete, long; the keystone-shaped (cuneate) mesoscutum starred with minute white setigerous dots, also present on the parapsides but absent elsewhere. Scutellum regularly rectangular, longer than wide. Abdomen sessile, ovipositor not exserted, long. Abdomen ovate, clothed with paired rows of minute setae. Antennæ 9-jointed scape, pedicel, 1 ring-joint, 3-jointed funicle and 3-jointed club; subclavate. Scape normal, slightly compressed, only moderate in length; pedicel obconic, somewhat longer than any of the following joints; ring-joint very short, like a lamella; funicle joints 2 and 3 subequal, slightly wider than long, 1 subquadrate, slightly longer than wide; club cylindrical-ovate, its proximal two joints slightly wider than long, each larger than any of the funicle joints, more than thrice the size of the small apical joint which is conical and terminates in a stout, spur-like seta arising from its center. Funicle and club joints bearing, as seen from any single aspect, several conspicuous, oblique white sulci. Vertex sparsely pubescent.

Male:-Length $1.25 \mathrm{~mm}$; somewhat more robust than the other sex. Entirely different in color and in certain structures. General color light honey yellow, contrasting with the female; only the dorsal aspect of the abdomen, the femora, the distal tarsal joint and the antennal scape darker, nearly fuscous, the 
antennal flagellum, however, greyish black; venation greyish brown, the fore wings uniformly, rather lightly, fumated throughout. Differing from the female in the following characters: the fore wings are perfect but very small and the stigmal vein is absent; the posterior wings are reduced in proportion. The tibial spur is lengthened, especially on the caudal legs; the antennæ are more compact, the scape enormously enlarged, but the appendage is 9-jointed if a ring-joint is present, which I doubt; the pedicel is short and attached to the inner side of the scooplike portion of the scape and is wider than long; all funicle joints wider than long, the first short, transverse, not a third of the length of either the second or third, which are subequal and large; club as in the female, but it is somewhat more compact and the terminal spur is just traceable as a nipple-like projection from the apex. Body subhispid, the pubescence especially noticeable over the whole abdomen and on the antennal scape; sulci on flagellum reduced and present on the club joints only. Fore wing bearing about eight lines of discal ciliation; its marginal cilia are short.

Described from three males and ten females received for identificaton from Mr. Henry Tryon, Government Entomologist and Vegetable Pathologist, Department of Agriculture and Stock, Brisbane, mounted in balsam on two slides labelled, "Host, Pison spinoloe (Hym.) Mt. Tambourine, S. Queensland, Dept. Ag. \& S., 11; 12; 11."

Types: No. Hy. 997, Queensland Museum, Brisbane, two males, seven females on a single slide in balsam. Cotypes-One male, three females on a single balsam slide deposited in the collection of the Department of Agriculture and Stock, Brisbane.

Mr. Tryon informs me that the parasites emerged from the host in its cocoon but not until after it had transformed into the adult; the latter died. A number of the parasitic larvæ make their way out from each Pison and pupate nakedly.

This Melittobia, the first known from Australia, differs from a North American species as yet not identified but which is parasitic on the larva of Sceliphorn cementarium, the common mud dauber of the United States, in a number of specific characters, all distinct but none marked. The shape of the antennal joints differs, the coloration and the pubescence or ciliation of the wings. I could not discover a ring-joint in the male of the American species either and have reason to think it is absent. 

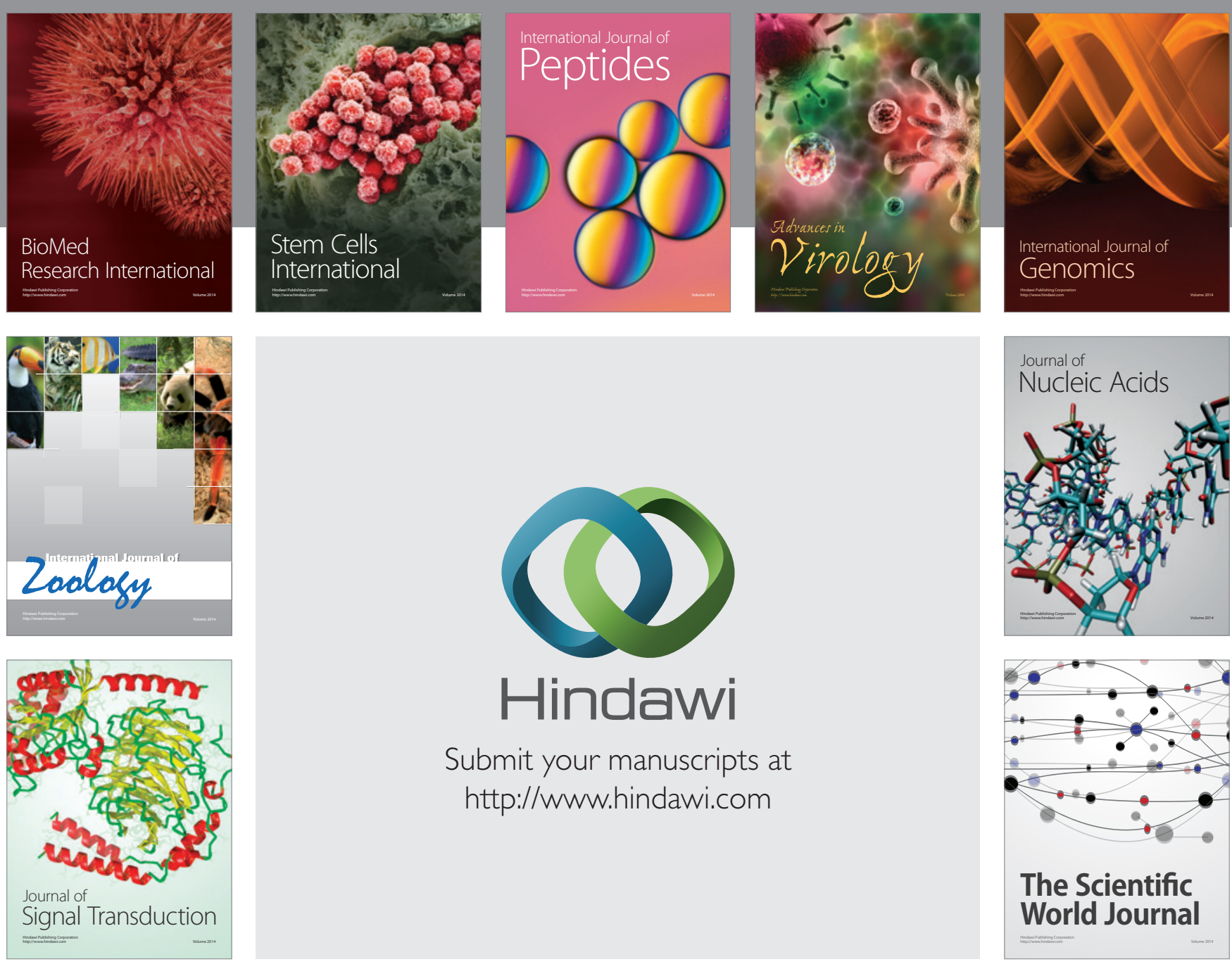

Submit your manuscripts at

http://www.hindawi.com
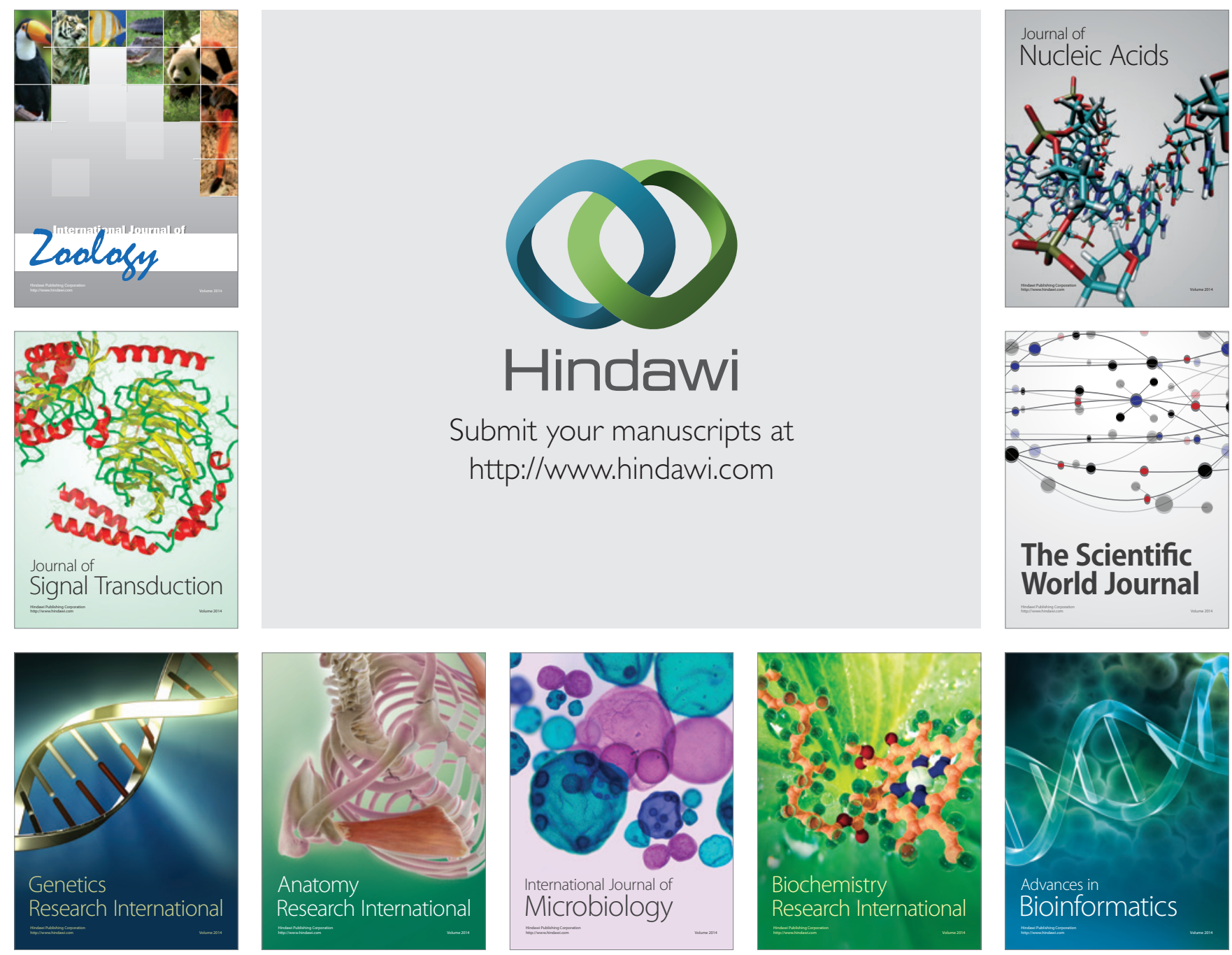

The Scientific World Journal
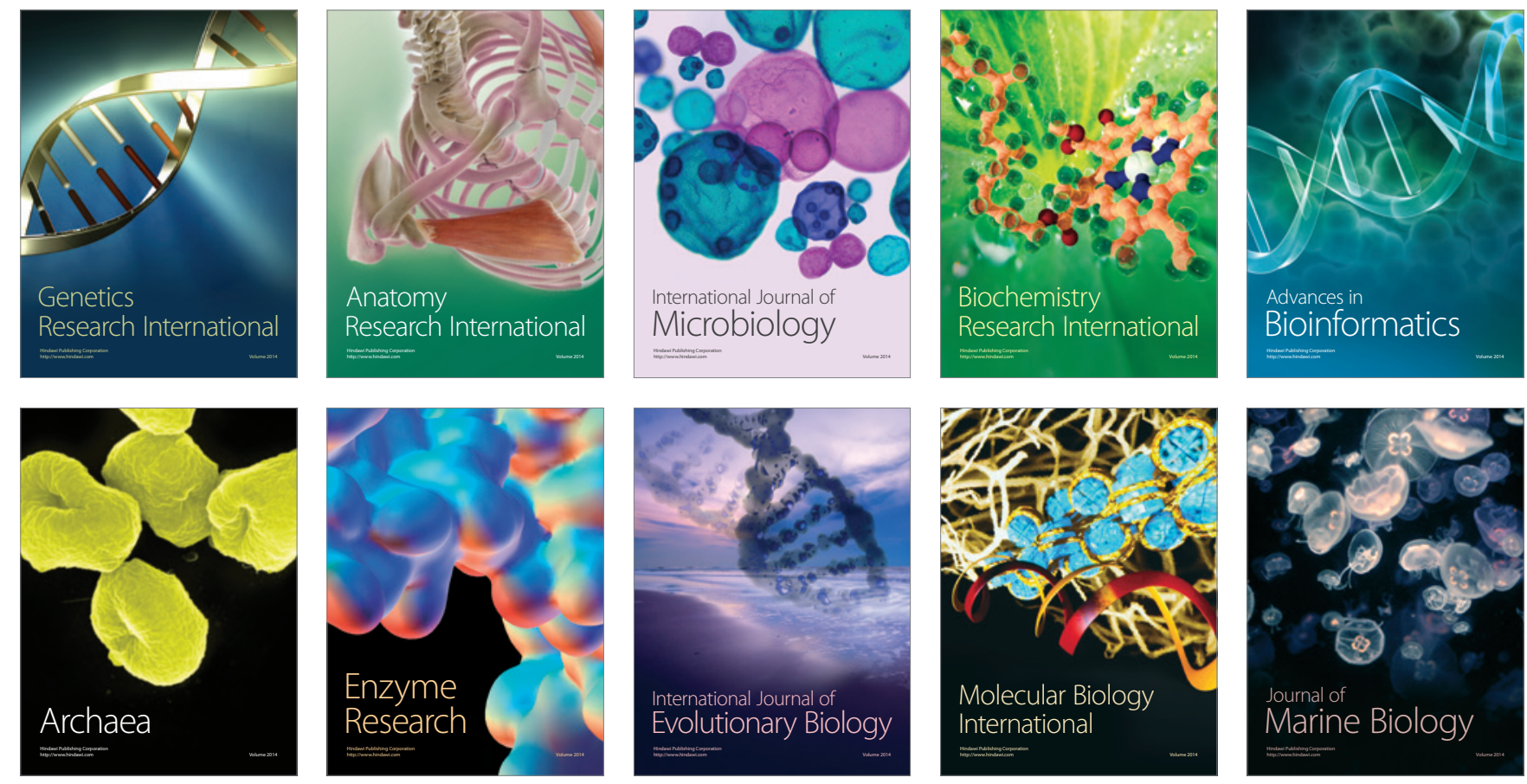